Muntadher I. Rahmah* and Noor M. Saadoon, Afrah J. Mohasen, Reham I. Kamel, Tabark A. Fayad, and Noor M. Ibrahim

\title{
Double hydrothermal synthesis of iron oxide/silver oxide nanocomposites with antibacterial activity**
}

https://doi.org/10.1515/jmbm-2021-0021

Received Jul 19, 2021; accepted Sep 20, 2021

\begin{abstract}
In this work, iron oxide "gamma phase" $\left(\gamma-\mathrm{Fe}_{2} \mathrm{O}_{3}\right)$ silver oxide $\left(\mathrm{Ag}_{2} \mathrm{O}\right)$ nanocomposite is prepared by a double hydrothermal method combined with Punicaceae plant extract as reducing agents. X-ray diffraction (XRD) results confirmed the presence of $\gamma-\mathrm{Fe}_{2} \mathrm{O}_{3}$ and $\mathrm{Ag}_{2} \mathrm{O}$ and delafossite silver ferrite $\left(\mathrm{AgFeO}_{2}\right)$ phases. Field Emission Scanning Electron Microscopy-energy dispersive spectroscopy (FESEMEDS) results revealed nanoparticles (NPs) with a shape like a cauliflower plant. Furthermore, the anti-bacterial activity results presented high inhibition rates against Klebsiella pneumoniae, Staphylococcus aureus, Staphylococcus epidermidis, Escherichia coli, and Candida albicans. The present study exhibits a new approach to the preparation of metal oxides using a facile and inexpensive method.
\end{abstract}

Keywords: hydrothermal, silver oxide, nanostructures, antibacterial activity

\section{Introduction}

Nanostructures have attracted unparalleled interest due to their unusual properties that differ greatly from their bulk state due to the increased surface area to volume ratio that increases the reactivity of surface electrons in materials [1] Metallic oxides nanostructures have many applications, especially in optoelectronic systems, biomedicine, catalytic systems, and antimicrobial activity [2]. $\mathrm{Ag}_{2} \mathrm{O}$ have been extensively studied due to their great antibacterial activity and unique photoelectric properties. Its exhibit various modes of inhibiting microorganisms and are well-known antimicrobial agents due to their low production costs [3]

\footnotetext{
*Corresponding Author: Muntadher I. Rahmah: Medical Instrumentation Engineering Department, Al-Esraa University College, Baghdad, Iraq, E-mail: superhydrophobicsurfaces@mail.ru

Noor M. Saadoon, Afrah J. Mohasen, Reham I. Kamel, Tabark A. Fayad, and Noor M. Ibrahim: Medical Instrumentation Engineering Department, Al-Esraa University College, Baghdad, Iraq
}

As a semiconductor matter, $\mathrm{Ag}_{2} \mathrm{O}$ is known to have a wide bandgap that may exceed $2.4 \mathrm{eV}[4,5] \cdot \gamma-\mathrm{Fe}_{2} \mathrm{O}_{3}$ nanostructures consist of iron and oxygen and have an energy gap of about $2.2 \mathrm{eV}$ with a high absorption capacity for the visible light spectrum $[6,7,8]$. Due to its non-toxicity and low cost due to its superior magnetic properties, it is used in wide applications, especially in the fields of photocatalysts, drug delivery, durable dyes ultra, diagnostic MRI, waterproofing, heat therapy and microbial inhibition $[9,10]$. In the same context, the incorporation of metallic nano-oxides with each other is one of the important ways to improve the properties of these materials, especially their structural, optical and morphological properties, as well as their antibacterial properties [11, 12, 13]. The green plant extracts method is considered efficient and effective for the preparation of metal oxide nanostructures based on the active compounds in plants [14]. The primary mechanism in this process is plant-assisted reduction due to phytochemicals such as carboxylic acids, amides, quinones, terpenoids, ketones flavones, organic acids, and aldehydes. The phytochemicals are responsible for the immediate reduction of ions. It was suggested that the phytochemicals are affected directly in the reduction of ions and the creation of NPs. The active compound present in the plant extract reduces the monovalent metal ion to uncharged atoms that aggregate to reach nano-size $[15,16]$. The Punicaceae plant extract contains many active compounds maybe acts as a reducing agent to formation NPs, such as ascorbic acid $\left(\mathrm{C}_{6} \mathrm{H}_{8} \mathrm{O}_{6}\right)$, gallic acid $\left(\mathrm{C}_{7} \mathrm{H}_{6} \mathrm{O}_{5}\right)$, and flavonoe $\left(\mathrm{C}_{15} \mathrm{H}_{10} \mathrm{O}_{2}\right)[17,18,19]$. The current study aims to (i) fabrication of $\gamma-\mathrm{Fe}_{2} \mathrm{O}_{3}-\mathrm{Ag}_{2} \mathrm{O}$ nanocomposite by inexpensive hydrothermal method and Punicaceae plant extract as reducing agents (ii) characterizing the optical, structural and morphological properties of the nanocomposite (iii) study the anti-bacterial activity of nanocomposite against gram-positive negative bacteria and gram-positive fungi cultures.

\footnotetext{
**Paper included in the Special Issue entitled: Proceedings of Mustansiriyah International Conference on Applied Physics - 2021 (MICAP2021)
} 


\section{Experimental}

\subsection{Materials}

The materials used for the manufacture were silver nitrate $\left(\mathrm{AgNO}_{3}, 99.98 \%\right.$, Aldrich), iron nitrate $\left[\mathrm{Fe}\left(\mathrm{NO}_{3}\right)_{3} .9 \mathrm{H}_{2} \mathrm{O}\right]$, Merck Millipore, 99\%], and sodium hydroxide [NaOH, Scharlau, 98\%]. The punicaceae plant was obtained from the local market in Iraq-Baghdad. The distilled water (DW) water was used throughout this study.

\subsection{Preparation of Punicaceae plant extract}

$30 \mathrm{~g}$ of Punicaceae plants (pulp) was rinsed with DW to remove any impurities and dust. Then, the pulp was mixed with $250 \mathrm{~mL}$ of DW and boiled at a suitable temperature. After a while, the solution was filtered with filter paper (Whatman No.4 and pore size $20 \mu \mathrm{m}$ ) and centrifuge at (3000) rpm. Finally, the plant extracts are using for the fabrication of $\gamma-\mathrm{Fe}_{2} \mathrm{O}_{3}-\mathrm{Ag}_{2} \mathrm{O}$ nanocomposite.

\subsection{Fabrication of $\gamma-\mathrm{Fe}_{2} \mathrm{O}_{3}-\mathrm{Ag}_{2} \mathrm{O}$ nanocomposite}

In a typical fabrication,

First; $1 \mathrm{~g}$ of $\left(\mathrm{Fe}\left(\mathrm{NO}_{3}\right)_{3} .9 \mathrm{H}_{2} \mathrm{O}\right)$ and $1 \mathrm{~g}$ of $\mathrm{AgNO}_{3}$ were dissolved in $50 \mathrm{ml}$ of DW under magnetic stirring for $30 \mathrm{~min}$ to obtain solation with a molar ratio of 13:9 (silver nitrate to iron nitrate). After the homogeneous of solution $6 \mathrm{ml}$ of Punicaceae plant Extracts was added. Then $5 \mathrm{ml}$ of $50 \mathrm{mM}$ of $\mathrm{NaOH}(\mathrm{pH}=11)$ was added above the solution to obtain a reddish-black precipitate. After this, the precipitate was collected using centrifugation, regularly rinsed with DW and ethanol. Finally dried in an oven at $80 \mathrm{C}$.

Second; $1 \mathrm{~g}$ of reddish-black precipitate and $0.5 \mathrm{~g} \mathrm{(8.3}$ $\mathrm{mM}$ ) of urea were suspended in $100 \mathrm{ml}$ of DW under magnetic stirring for $30 \mathrm{~min}$. After homogenate, the solution was put inside an autoclave and sealed tightly then placed in the oven at $120^{\circ} \mathrm{C}$ for $2 \mathrm{~h}$. The precipitate was collected using centrifugation and rinsed with both DW and ethanol to get clean precipitate.

Third, the double hydrothermal method was used to decorate the precipitate via dissolved $70 \mathrm{mg}(5 \mathrm{mM})$ of $\mathrm{AgNO}_{3}$ and $0.7 \mathrm{~g}$ of reddish-black precipitate in $80 \mathrm{ml}$ of DW under stirring for $30 \mathrm{~min}$. Subsequently, $5 \mathrm{ml}$ of $\mathrm{NaOH}$ was added to the as-prepared precursor solution. Then the solution was dissolved inside an autoclave and sealed tightly then placed in the oven at $120{ }^{\circ} \mathrm{C}$ for $2 \mathrm{~h}$. The resulting black precipitate was collected by centrifugation, repeat- edly washed with DW ten times and ethanol four times and dried at $75^{\circ} \mathrm{C}$ for $3 \mathrm{~h}$.

\subsection{Characterization}

The crystal phase compositions the nanocomposite were studied using XRD (Miniflex II Rigaku, Japan) with a $\mathrm{Cu}$ $\mathrm{K} \alpha$ radiation $(\lambda=1.5408 \AA)$. The data in this work matching with $2 \Theta$ and intensity of XRD patterns of ICDD database (International Centre for Diffraction Data). The morphology of the sample was studied by FESEM-DES (Zeiss Sigma VPGermany). The optical properties were analyzed using a xenon lamp spectrophotometer (Split-beam Optics, Dual detectors, made in Japan).

\subsection{Antimicrobial activity}

The antimicrobial activity of $\gamma-\mathrm{Fe}_{2} \mathrm{O}_{3}-\mathrm{Ag}_{2} \mathrm{O}$ nanocomposite was examined against bacterial cultures Gram-positive (Staphylococcus aureus and Staphylococcus Epidermidis), Gram-negative (Escherichia coli and Klebsiella pneumonia), and against fungi cultures gram-positive (Candida albicans). We have opted for these five different types of pathogenic microbes because of the following reasons:

- Escherichia coli: naturally living in the gut and does not cause a disease, but virulent strains can cause diarrhea, neonatal meningitis, urinary tract infections, hemorrhagic colitis, neonatal meningitis, gastroenteritis, food poisoning, and sometimes fever [20].

- Klebsiella pneumoniae: causes many diseases such as very pneumonia, meningitis, diarrhea, urinary tract infections, sepsis, and soft tissue infections [21].

- Staphylococcus epidermidis: causes the growth of biofilms on "plastic devices" that are fixed inside the human body, usually covering intravenous medical catheters and prostheses [22].

- Staphylococcus aureus: causes food poisoning and skin infections including abscesses and respiratory infections. Pathogenic strains usually producing virulence agents such as potent protein toxins to increase infections [23].

- Candida albicans: caused by hospital-acquired infection. It considers the main source of fungal infection in immunocompromised patients or critically ill patients. Patients often develop thrush and oropharyngeal candidiasis, which affect drug absorption and cause malnutrition [24]. 
The agar well-diffusion method is using to evaluate the antimicrobial activity of sample. The nutrient agar medium was prepared by dissolving yeast extract that contributes vitamins, carbohydrates, nitrogen, and salts. Also, the peptone provides organic nitrogen. The ingredients are well mixed, then boiled, and poured into Petri-dishes until it becomes solidified. Then, the nanocomposite powder was dissolved in DMSO solvent at the concentration $(1 \mathrm{mg} / \mathrm{mL})$. Each well (diameter of $8 \mathrm{~mm}$ ) contains $50 \mu \mathrm{L}$ of a sample and DMSO solvent as control. Finally, the sterile Petri dishes (diameter of $90 \mathrm{~mm}$ ) were incubated at $\pm 25^{\circ} \mathrm{C}$ for $24 \mathrm{~h}$.

\section{Results and discussion}

\subsection{Structure and morphology of the as-synthesized materials}

\subsubsection{XRD investigation}

The XRD pattern of the as-prepared sample is shown in Figure 1. The results of XRD diffraction peaks exhibit characteristic peaks matching to the (222), (422), and (440) planes of $\mathrm{Fe}_{2} \mathrm{O}_{3}$ (ICDD Card No.00-039-0238); (200), (311), and (222) planes of Ag2O (ICDD Card No.00-001-1041); (004) and (101) planes of $\mathrm{AgFeO}_{2}$ (ICDD Card No.01-070-1452). The XRD pattern has sharp peaks that indicate a good crystallization.

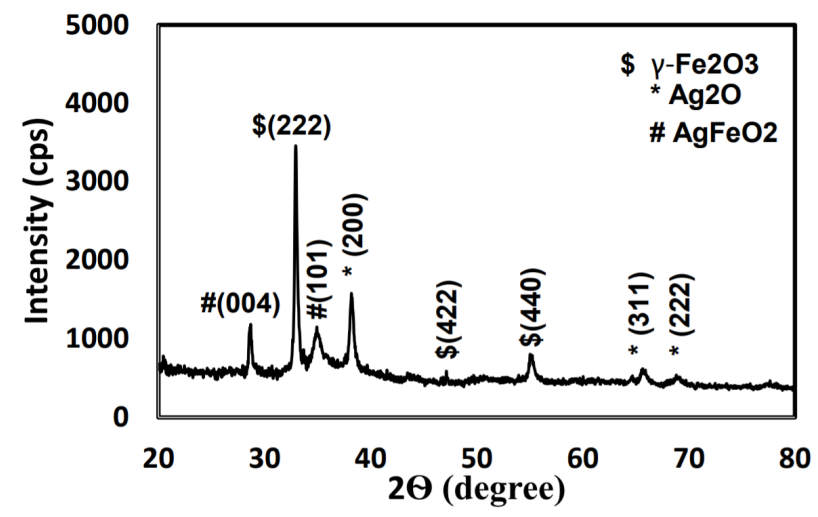

Figure 1: XRD pattern of $\gamma-\mathrm{Fe}_{2} \mathrm{O}_{3}-\mathrm{Ag}_{2} \mathrm{O}$ nanocomposite.

Debye-Scherrer equation using to calculate the average crystallite size of all phases, as shown in Table 1. It is estimated to be about (14.1-55.07) $\mathrm{nm}$ for $\gamma-\mathrm{Fe}_{2} \mathrm{O}_{3},(12.87-32.87)$ $\mathrm{nm}$ for $\mathrm{Ag}_{2} \mathrm{O}$, and (23.26-32.06) $\mathrm{nm}$ for $\mathrm{AgFeO}_{2}$. This discrepancy in crystal size may be attributed to the difference in ionic radius of iron ions $\left(\mathrm{Fe}^{+2}\right.$ and $\left.\mathrm{Fe}^{+3}\right)$ and silver ion $\left(\mathrm{Ag}^{+}\right)$, where $\mathrm{Fe}$ ions have ionic radius $\left(\mathrm{Fe}^{+2}\right.$ is $0.076 \mathrm{~nm}$ and $\mathrm{Fe}^{+3}$ is
$0.064 \mathrm{~nm})$ and $\mathrm{Ag}$ ion have an ionic radius $\left(\mathrm{Ag}^{+}\right.$is $\left.0.128 \mathrm{~nm}\right)$ $[25,26]$. The favorite direction trend for (222) and attributed to $\gamma-\mathrm{Fe}_{2} \mathrm{O}_{3}$ with cubic system structure.

\subsubsection{FESEM and EDS investigation}

Figure 2 shows the FESEM surface morphological structure image of $\gamma-\mathrm{Fe}_{2} \mathrm{O}_{3}-\mathrm{Ag}_{2} \mathrm{O}$ nanocomposite that synthesized by the double hydrothermal method. The results are shown in this figure demonstrate groups of NPs with different nanoshapes, like the cauliflower plant with an average size from $44.22 \mathrm{~nm}$ to $73.82 \mathrm{~nm}$.
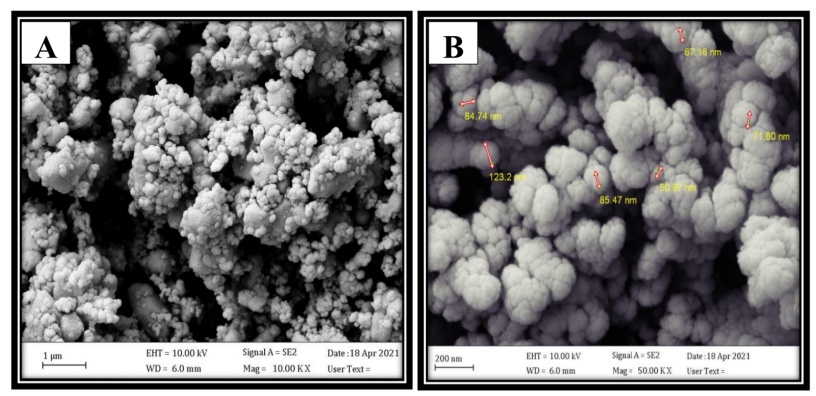

Figure 2: FESEM images of $\gamma-\mathrm{Fe}_{2} \mathrm{O}_{3}-\mathrm{Ag}_{2} \mathrm{O}$ nanocomposite at scale (A) $1 \mu \mathrm{m}$ and (B) $200 \mathrm{~nm}$.

Figure 3 (A) shows the EDS elemental composition spectrum of $\gamma-\mathrm{Fe}_{2} \mathrm{O}_{3}-\mathrm{Ag}_{2} \mathrm{O}$ nanocomposite, While Figure 3 (B, C) depicts the corresponding elemental mapping for $\mathrm{Ag}$ and O elements. It was observed that this nanocomposite was composed of Ag and O, indicating it is mainly AgNPs at the surface of the nanocomposite. The presence of gold $(\mathrm{Au})$ peaks here is due to the coating process.

\subsection{Optical measurements}

The UV-Vis absorption spectrum of $\gamma-\mathrm{Fe}_{2} \mathrm{O}_{3}-\mathrm{Ag}_{2} \mathrm{O}$ nanocomposite is shown in Figure 4, and the results demonstrated a sharp absorbance peak at a wavelength of $310 \mathrm{~nm}$. This peak corresponds to the formation of metal oxide nanostructures. In addition, a small absorption peak was observed at the wavelength of $375 \mathrm{~nm}$ and may be attributed to the surface plasmon of AgNPs.

The relation between photon energy and $(\alpha \mathrm{h} v)^{2}$ was used to calculate the energy gap (Eg) of $\gamma-\mathrm{Fe}_{2} \mathrm{O}_{3}-\mathrm{Ag}_{2} \mathrm{O}$ nanocomposite, as shown in Figure 5. The results confirm the nanocomposite has Eg of $3.05 \mathrm{eV}$. This blueshift of an absorption spectrum to an ultraviolet area (low wavelength) may be attributed to the inverse correlation between nano- 
Table 1: XRD parameters of $\gamma-\mathrm{Fe}_{2} \mathrm{O}_{3}-\mathrm{Ag}_{2} \mathrm{O}$ nanocomposite.

\begin{tabular}{llllll}
\hline Material & (hkl) & $2 \theta$ Exp. (deg.) & $2 \theta$ ICDD (deg.) & FWHM (deg.) & Crystallite size (nm) \\
\hline & 222 & 32.91 & 32.977 & 0.1535 & 53.98 \\
& 422 & 47.15 & 47.21 & 0.6140 & 14.12 \\
$\gamma-\mathrm{Fe}_{2} \mathrm{O}_{3}-\mathrm{Ag}_{2} \mathrm{O}$ nanocomposite & 440 & 55.07 & 55.22 & 0.2047 & 43.78 \\
& 200 & 38.17 & 38.10 & 0.2558 & 32.87 \\
& 311 & 65.6 & 65.7 & 0.5117 & 18.48 \\
& 222 & 68.9 & 68.99 & 0.7488 & 12.87 \\
& 004 & 28.58 & 28.78 & 0.2558 & 32.06 \\
& 101 & 34.9 & 34.82 & 0.3582 & 23.26 \\
\hline
\end{tabular}

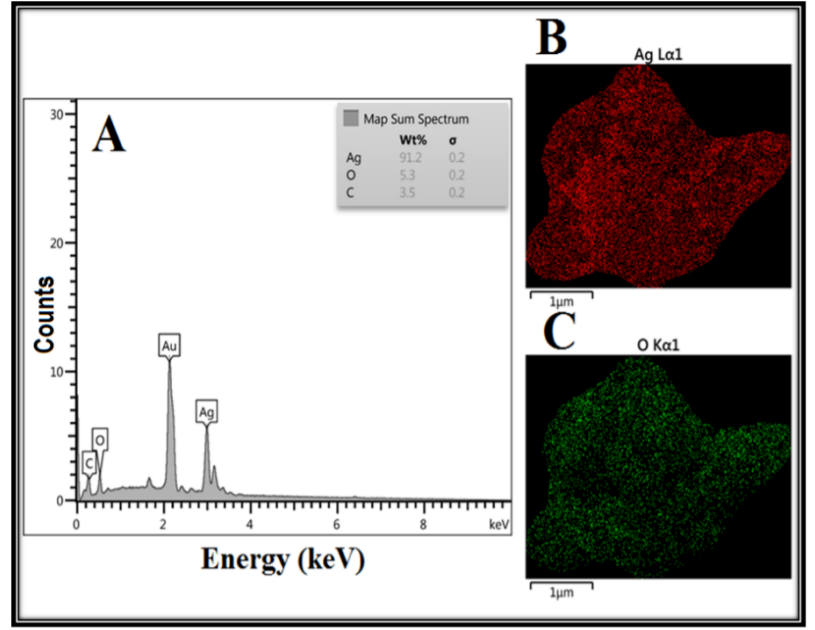

Figure 3: (A) EDS spectrum of $\gamma-\mathrm{Fe}_{2} \mathrm{O}_{3}-\mathrm{Ag}_{2} \mathrm{O}$ nanocomposite and its corresponding elemental mapping images for (B) silver and (C) oxygen.

size and Eg when the material is reduced to the nanoscale $[27,28]$. When the particle size reduces, the molecules and atoms (electrons) in NPs will be restricted and the overlapping between the orbitals of an atom becomes limited. And this causes board Eg between the conduction band and valence band $[28,29]$. This increase in the energy gap after mixing metal oxides is consistent with the results obtained in the work [30].

\subsection{Antibacterial activity}

Antibacterial activity against microorganisms is intrinsically dependent on the type and components of the cell wall. Bacteria are usually exposed to unusual environmental conditions. Accordingly, bacteria can withstand difficult conditions and modify themselves depending on their high ability to withstand the effects of extremely challenging environments. In other words, bacteria naturally have a very

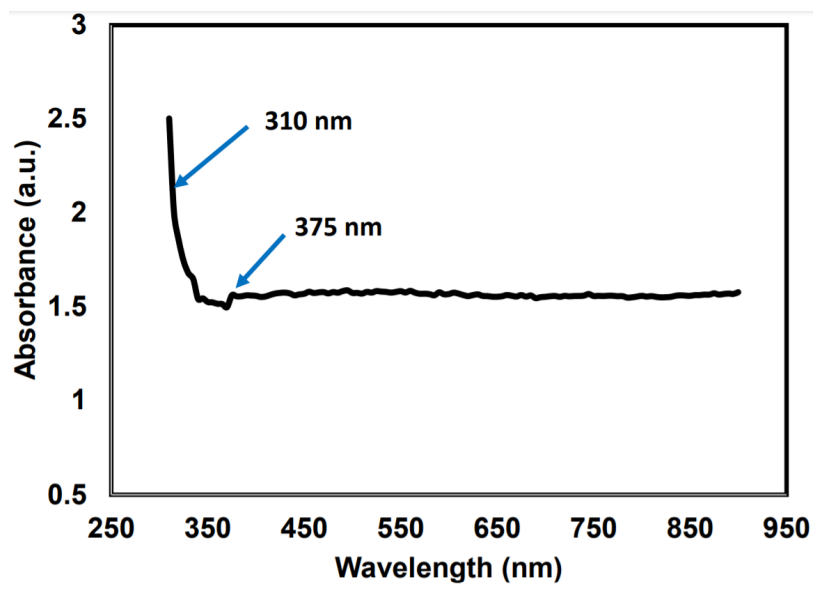

Figure 4: UV-Visible spectra of $\gamma-\mathrm{Fe}_{2} \mathrm{O}_{3}-\mathrm{Ag}_{2} \mathrm{O}$ nanocomposite.

powerful defense to deal with a variety of stressors, such as toxicity. Here, the hydrothermal synthesis of $\gamma-\mathrm{Fe}_{2} \mathrm{O}_{3}-\mathrm{Ag}_{2} \mathrm{O}$ nanocomposite used to study their antibacterial activity against Gram-positive bacteria (Staphylococcus aureus and Staphylococcus epidermidis), Gram-negative bacteria (Escherichia coli and Klebsiella pneumonia) and fungi cultures gram-positive (Candida albicans) as shown in Figure 6 The results of obtained inhibition zones are shown in Table 2 and indicate the highest antibacterial performance of the as-prepared specimen.

Before discussing the antibacterial activity, it is very important to regard that nanostructures are small particles and have a very high surface area within a very small size, which gives them properties that differ from their properties in the bulk case. According to the aforementioned, nanostructures work directly to inhibit the growth of bacteria by contacting their cell wall, and this, in turn, depends mainly on the surface area, the shape of the nanostructures, and their concentration.

The anti-bacterial activity of $\gamma-\mathrm{Fe}_{2} \mathrm{O}_{3}-\mathrm{Ag}_{2} \mathrm{O}$ nanocomposite is mainly associated with the release of silver ions $\left(\mathrm{Ag}^{+}\right)$and Iron oxide ions $\left(\mathrm{Fe}^{+2}\right.$ and $\left.\mathrm{Fe}^{+3}\right)$. Because these 


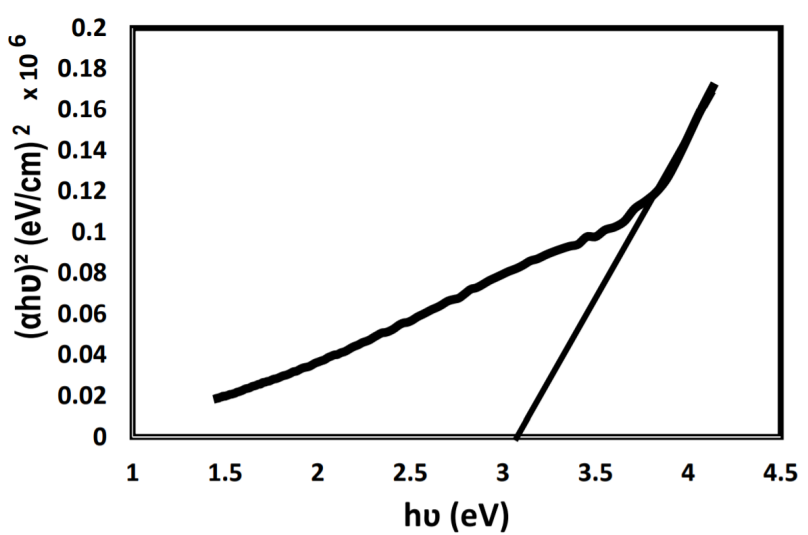

Figure 5: Direct band gap of $\gamma-\mathrm{Fe}_{2} \mathrm{O}_{3}-\mathrm{Ag}_{2} \mathrm{O}$ nanocomposite.

ions can bind to the cell wall of bacteria through electrostatic attraction and reacted with the thiol group of bacteria cell-wall and blocked the transport of nutrients through the cell wall and finally the bacteria death. Also, those ions can interact with the base of DNA and affect its replication, then causing cellular death(31). And in the case of metal oxides, the reactive oxygen species (ROS) can play an important role in inhibiting bacterial growth through oxidative stress and reduction processes that greatly affect the bacterial or fungal cell components(32).

Table 2: The inhibition zone results of $\gamma-\mathrm{Fe}_{2} \mathrm{O}_{3}-\mathrm{Ag}_{2} \mathrm{O}$ nanocomposite.

\begin{tabular}{|c|c|c|c|}
\hline Type of microbial & $\begin{array}{l}\text { Inhibition } \\
\text { zone } \\
(\mathrm{mm})\end{array}$ & $\begin{array}{l}\text { Inhibition } \\
\text { percent- } \\
\text { age \% }\end{array}$ & Control \\
\hline Escherichia coli & 13.5 & 15 & 0 \\
\hline Klebsiella pneumonia & 13 & 14.4 & 0 \\
\hline $\begin{array}{l}\text { Staphylococcus epi- } \\
\text { dermidis }\end{array}$ & 13 & 14.4 & 0 \\
\hline $\begin{array}{l}\text { Staphylococcus au- } \\
\text { reus }\end{array}$ & 18 & 20 & 0 \\
\hline Candida albicans & 13 & 14.4 & 0 \\
\hline
\end{tabular}

\section{Conclusions}

The study demonstrated a promising and generally applicable approach to fabricate $\gamma-\mathrm{Fe}_{2} \mathrm{O}_{3}-\mathrm{Ag}_{2} \mathrm{O}$ nanocomposite using a double hydrothermal method and Punicaceae plant Extract as reducing agents. XRD results showed the presence phases of elementals $\mathrm{Fe}_{2} \mathrm{O}_{3}, \mathrm{Ag}_{2} \mathrm{O}$, and $\mathrm{AgFeO} 2$

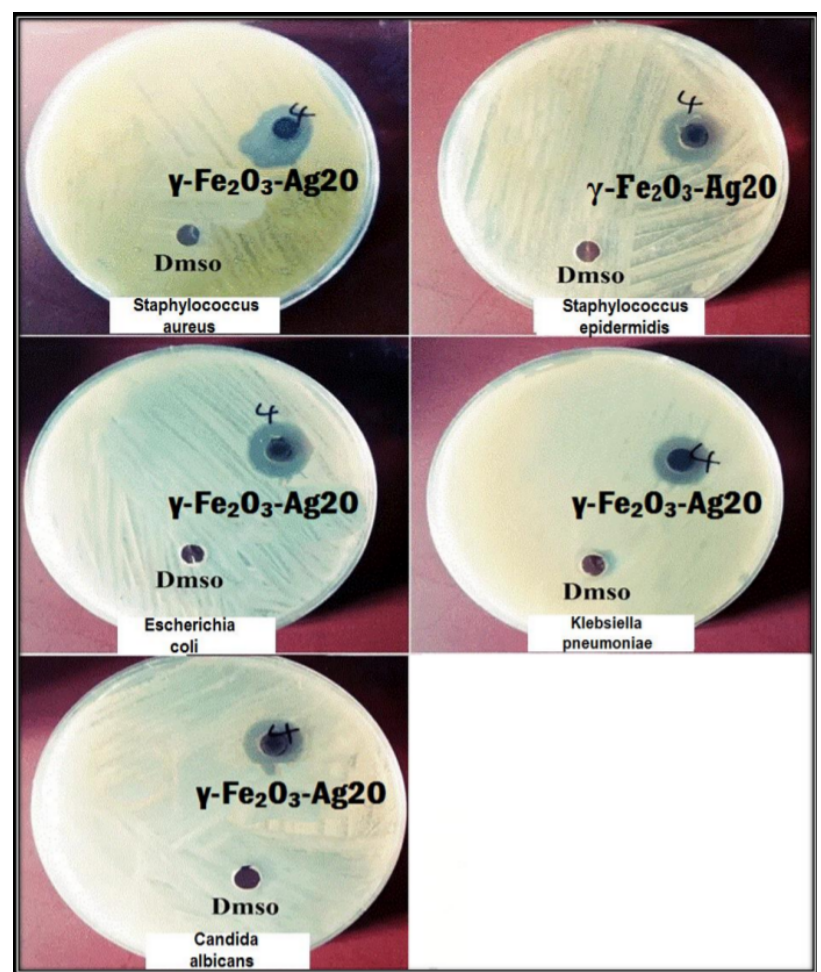

Figure 6: The antibacterial activity of $\gamma-\mathrm{Fe}_{2} \mathrm{O}_{3}-\mathrm{Ag}_{2} \mathrm{O}$ nanocomposite against (A)Staphylococcus aureus, (B) Staphylococcus epidermidis, (C) Escherichia coli , (D) Klebsiella pneumonia and (E) Candida albicans.

with average crystallite sizes of $37 \mathrm{~nm}, 27.8 \mathrm{~nm}$, and 27.6 $\mathrm{nm}$, respectively. FESEM results demonstrated groups of NPs like the cauliflower plant with an average size diameter (44.22 - 73.82) $\mathrm{nm}$. EDS spectra and mapping results showed the presence of the energy peaks of $\mathrm{Ag}$ and $\mathrm{O}$ elements only. This indicating the AgNPs located at the surface of the nanocomposite. The antimicrobial screening suggests that synthesized nanocomposite exhibited moderate activity toward Klebsiella pneumoniae. and high activity toward Staphylococcus aureus, Staphylococcus epidermidis, Escherichia coli, and Candida albicans fungi. One unique observation was that nanocomposite synthesized demonstrated the maximum zone of inhibition in the case of Staphylococcus aureus. Accordingly, the results revealed the high ability to inhibit various types of Gram-negative, Gram-negative bacteria, and Candida albicans fungi.

Acknowledgement: The authors would like to thank AlEsraa University College, Baghdad, Iraq for its support in the present work.

Funding information: The authors state no funding involved. 
Author contributions: All authors have accepted responsibility for the entire content of this manuscript and approved its submission.

Conflict of interest: The authors state no conflict of interest.

\section{References}

[1] Natarajan S, Aifantis K. Size effects in nanostructured Li-ion battery cathode particles. J Mech Behav Mater. 2020;29(1):3643.

[2] Ghotekar S, Dabhane H, Pansambal S, Oza R, Tambade P, Med hane V. A Review on Biomimetic Synthesis of Ag20 Nanoparticles using Plant Extract, Characterization and its Recent Applications. Adv J. Chem-Sect B. 2020:102-11.

[3] Haq S, Yasin KA, Rehman W, Waseem M, Ahmed MN, Shahzad MI, et al. Green synthesis of silver oxide nanostructures and investigation of their synergistic effect with moxifloxacin against selected microorganisms. J Inorg Organomet Polym Mater. 2021;31(3):1134-42.

[4] Haq S, Rehman W, Waseem M, Meynen V, Awan SU, Saeed S, et al. Fabrication of pure and moxifloxacin functionalized silver oxide nanoparticles for photocatalytic and antimicrobial activity. J Photochem Photobiol B: Biol. 2018;186:116-24.

[5] Ribeiro R, Oliveira M, Bomio M, de Lazaro SR, Andrés J, Longo E. Connecting the surface structure, morphology and photocatalytic activity of Ag20: An in depth and unified theoretical investigation. Appl Surf Sci. 2020;509:145321.

[6] Farahmandjou M, Soflaee F. Synthesis and characterization of $\alpha$-Fe203 nanoparticles by simple co-precipitation method. Phys Chem Res. 2015;3(3):191-6.

[7] Hitam C, Jalil A. A review on exploration of $\mathrm{Fe} 2 \mathrm{O} 3$ photocatalyst towards degradation of dyes and organic contaminants. J Environ Manag. 2020;258:110050.

[8] Rahmah MI, Sabry RS, Aziz WJ. Preparation and photocatalytic property of $\mathrm{Fe} 2 \mathrm{O} 3 / \mathrm{ZnO}$ composites with superhydrophobicity. Int J Miner, Metall Mater. 2021;28(6):1072-9.

[9] Muhajir M, Puspitasari P, Razak JA. Synthesis and Applications of Hematite $\alpha$-Fe203: a Review. J Mechl Eng Sci Technol (JMEST). 2020;3(2):51-8.

[10] Luengo Y, Sot B, Salas G. Combining Ag and $\gamma$-Fe203 properties to produce effective antibacterial nanocomposites. Colloids Surf B: Biointerfaces. 2020;194:111178.

[11] El-Khouly SM, Fathy NA. M ulti-walled carbon nanotubes supported amorphous $\mathrm{Fe} 2 \mathrm{O} 3$ and $\mathrm{Ag} 2 \mathrm{O}-\mathrm{Fe} 2 \mathrm{O} 3$ as F enton catalysts for degradation of $m$ axilon red dye. Asia-Pacific J Chem Eng. 2018;13(3):e2184.

[12] Galedari M, Ghazi MM, Mirmasoomi SR. Novel visible-driven Ag2O/Fe203/TiO2 nano sized hetero-structured photocatalyst: Synthesis, characterization and photo-degradation of tetracycline. Chem Eng Res Design. 2021;170:248-55.

[13] Marques R, Ferrari-Lima A, Slusarski-Santana V, FernandesMachado N. Ag2O and Fe2O3 modified oxides on the photocatalytic treatment of pulp and paper wastewater. J Environ Manag. 2017;195:242-8.
[14] Sivakumar T. A modern review of silver nanoparticles mediated plant extracts and its potential bioapplications. Int J Botany Studies. 2021;6(3):170-5.

[15] Kasthuri J, Veerapandian S, Rajendiran N. Biological synthesis of silver and gold nanoparticles using apiin as reducing agent. Colloids Surf B: Biointerfaces. 2009;68(1):55-60.

[16] Jha AK, Prasad K, Prasad K, Kulkarni A. Plant system: nature's nanofactory. Colloids Surf B: Biointerfaces. 2009;73(2):219-23.

[17] Mohammad SM, Kashani HH. Chemical composition of the plant Punica granatum L.(Pomegranate) and its effect on heart and cancer. J Medicin Plants Res. 2012;6(40):5306-10.

[18] Naz S, Khaskheli AR, Aljabour A, Kara H, Talpur FN, Sherazi STH, et al. Synthesis of highly stable cobalt nanomaterial using gallic acid and its application in catalysis. Adv Chem. 2014;686925.

[19] Sreekumar S, Sithul H, Muraleedharan P, Azeez JM, Sreeharshan S. Pomegranate fruit as a rich source of biologically active compounds. BioMed Res Int. 2014;2014.

[20] Kaper JB, Nataro JP, Mobley HL. Pathogenic escherichia coli. Nature Rev Microbiol. 2004;2(2):123-40.

[21] Massinga AJ, Garrine M, Messa A, Nobela NA, Boisen N, Massora $S$, et al. Klebsiella spp. cause severe and fatal disease in Mozambican children: antimicrobial resistance profile and molecular characterization. BMC Infect Diseases. 2021;21(1):526.

[22] Méric G, Mageiros L, Pensar J, Laabei M, Yahara K, Pascoe B, et al. Disease-associated genotypes of the commensal skin bacterium Staphylococcus epidermidis. Nature Commun. 2018;9(1):1-11.

[23] Cheung GY, Bae JS, Otto M. Pathogenicity and virulence of Staphylococcus aureus. Virulence. 2021;12(1):547-69.

[24] Henriques M, Silva S. Candida albicans virulence factors and its pathogenicity. Microorganisms. 2021;9(4):704.

[25] Cacciotti I. Cationic and anionic substitutions in hydroxyapatite. Handbook Bioceram Biocompos. 2016:145-211.

[26] Zhang X, Liang G, Xu Z. Defect structure and holographic storage properties of LiNb03: $\mathrm{Zr}$ : Fe: Cu crystals with various Li/Nb ratios. Optic Mater. 2019;96:109318.

[27] Chukwuocha EO, Onyeaju MC, Harry TS. Theoretical studies on the effect of confinement on quantum dots using the brus equation. World J Cond Matt Phys. 2012;2(2): 96-100.

[28] Rao LS, Rao TV, Naheed S, Rao PV. Structural and optical properties of zinc magnesium oxide nanoparticles synthesized by chemical co-precipitation. Mater Chem Phys. 2018;203:133-40.

[29] Arshad M, Ansari MM, Ahmed AS, Tripathi P, Ashraf S, Naqvi A, et al. Band gap engineering and enhanced photoluminescence of $\mathrm{Mg}$ doped $\mathrm{ZnO}$ nanoparticles synthesized by wet chemical route. J Luminescence. 2015;161:275-80.

[30] Febiyanto, Eliani IV, Riapanitra A, Sulaeman U, editors. Synthesis and visible light photocatalytic properties of iron oxide-silver orthophosphate composites. AIP Conf Proc; 2016: AIP Publishing LLC.

[31] Marambio-Jones C, Hoek EM. A review of the antibacterial effects of silver nanomaterials and potential implications for human health and the environment. J Nanoparticle Res. 2010;12:153151.

[32] Thukkaram M, Sitaram S, Subbiahdoss G. Antibacterial efficacy of iron-oxide nanoparticles against biofilms on different biomaterial surfaces. Int J Biomater. 2014;2014. 